\title{
The utility of C-reactive protein and procalcitonin for sepsis diagnosis in critically burned patients: A preliminary study
}

\author{
Juan J Egea-Guerrero MD PhD, Carmen Martínez-Fernández MD, Ana Rodríguez-Rodríguez PhD, \\ Angélica Bohórquez-López MD, Angel Vilches-Arenas MD PhD, María Pacheco-Sánchez CCNS, \\ Juan M Guerrero MD PhD, Francisco Murillo-Cabezas MD PhD
}

\begin{abstract}
JJ Egea-Guerrero, CMartínez-Fernández, A RodríguezRodríguez, et al. The utility of C-reactive protein and procalcitonin for sepsis diagnosis in critically burned patients: A preliminary study. Plast Surg 2015;23(4):239-243.

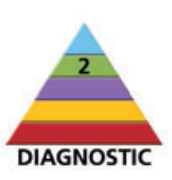

OBJECTIVE: To assess the utility of C-reactive protein (CRP) and procalcitonin (PCT) as biomarkers of infection in patients with severe burn injury. METHODS: The present study included severe burn injury patients consecutively admitted to the Virgen del Rocío University Hospital (Andalucia, Spain) intensive care unit during a 12 -month period. The variables of interest were: age, sex, mechanism of injury, percentage of burned body surface area, the Abbreviated Burn Severity Index (ABSI) and the absence/presence of sepsis. The authors analyzed serum levels of CRP and PCT at admission and every $48 \mathrm{~h}$ thereafter until intensive care unit discharge or death. Each determination was considered to be a sample or unit of analysis.

RESULTS: A total of 157 determinations were analyzed from 17 severe burn injury patients. Fifty-four samples were considered to be septic, 25 of which corresponded to the first day of a new onset of sepsis. The mean duration of these symptoms was four days (interquartile range two to five days). Significant differences were found in the distributions of CRP and PCT values between sepsis and no-sepsis samples. Analysis of the changes in these biomarkers over time showed that PCT increase $(\triangle \mathrm{PCT})$ differentiated these diagnoses, whereas CRP increase $(\triangle \mathrm{CRP})$ did not. ROC curve analysis revealed that $\triangle \mathrm{PCT}$ could predict positive sepsis samples (area under the curve 0.75 [95\% CI 0.58 to 0.90 ]; $\mathrm{P}=0.003$ ).

CONCLUSION: These preliminary results showed that PCT had a better discriminatory capacity than CRP for identifying infectious processes in patients with severe burn injury. A larger sample size would be needed to confirm these results.
\end{abstract}

Key Words: C-reactive protein; Critically burned patient; Infection; Procalcitonin; Sepsis

$\mathrm{O}$ ver the past few years, the number of critically burned patients in developed countries has increased, mostly due to workplace accidents and, to a lesser extent, to suicide attempts $(1,2)$. Improvement in prehospital care and early detection of immediate complications related to burn injuries have made multiple organ failure the major cause of death for these patients if they survive the first $24 \mathrm{~h}$. Sepsis, marked by changes in patient status that indicate the presence of both infection and systematic inflammatory response, is the cause of mortality in $28 \%$ to $65 \%$ of these cases (3-8).

An organism's pathophysiological response to burn injury is to release proinflammatory substances, in most cases leading to systemic inflammatory response syndrome (SIRS) and its clinical manifestations (8). Numerous factors can trigger this response, ranging from moment of injury, escharotomy, multiple surgeries for wound healing and skin grafting, to surgical procedures unrelated to burns, multiple transfusions and, especially, nosocomial infections $(7,9)$. This complex situation, in which multiple stimuli generate the same symptoms, makes sepsis diagnosis difficult and requires the use of strict criteria adapted to the burn population (9). Presently, nonspecific biochemical markers accompanying SIRS, including C-reactive protein (CRP) and

\section{L'utilité de la protéine $\mathrm{C}$ réactive et de la procalcitonine pour diagnostiquer un sepsis chez des grands brûlés : une étude préliminaire}

OBJECTIF : Évaluer l'utilité de la protéine C réactive (PCR) et de la procalcitonine (PCT) comme biomarqueurs de l'infection chez des grands brûlés. MÉTHODOLOGIE : La présente étude portait sur des grands brûlés admis consécutivement à l'unité de soins intensifs de l'hôpital universitaire Virgen del Rocío d'Andalousie, en Espagne, sur une période de 12 mois. Les variables étudiées étaient l'âge, le sexe, le mécanisme de brûlure, le pourcentage de surface corporelle brûlée, l'indice abrégé de gravité des brûlures (ABSI) et l'absence ou la présence de sepsis. Les auteurs ont analysé les taux sériques de PCR et de PCT des patients à l'admission, puis toutes les 48 heures jusqu'à leur congé des soins intensifs ou à leur décès. Chaque déterminant était considérée comme un échantillon ou une unité d'analyse.

RÉSULTATS : Au total, les auteurs ont analysé 157 déterminants chez 17 grands brûlés. Cinquante-quatre échantillons étaient considérés comme septiques, dont 25 correspondaient au premier jour d'apparition du sepsis. Les symptômes duraient en moyenne quatre jours (plage interquartile de deux à cinq jours). Les auteurs ont constaté des différences importantes dans la répartition des valeurs de PCR et de PCT entre les échantillons de sepsis et sans sepsis. L'analyse des changements de ces biomarqueurs au fil du temps a révélé que l'augmentation de la PCT $(\triangle \mathrm{PCT})$ distinguait ces diagnostics, contrairement à l'augmentation de la PCR ( $\triangle \mathrm{PCR})$. L'analyse de la courbe ROC a révélé que la $\triangle \mathrm{PCT}$ pouvait prédire des échantillons de sepsis positifs (aire sous la courbe de 0,75 [95\% IC 0,58 à 0,90]; P=0,003).

CONCLUSION : Les résultats préliminaires démontrent que la PCT avait une meilleure capacité discriminatoire que la PCR pour dépister les processus infectieux chez des grands brûlés. Il faudrait un plus gros échantillon pour confirmer ces résultats.

procalcitonin (PCT), act as specific biomarkers of infection (10-15). However, their usefulness in diagnosing sepsis in critically burned patients is not well defined (16-19). Therefore, the aim of the present study was to assess the utility of CRP and PCT for sepsis diagnosis in patients with severe burn injury.

Patients and samples

\section{METHODS}

Patients in the present study included severe burn injury patients $>14$ years of age, consecutively admitted to the Virgen del Rocío University Hospital (Andalucia, Spain) intensive care unit (ICU) during a 12 -month period. The protocol, in accordance with the Declaration of Helsinki, was approved by the hospital's institutional review board. Written consent to conduct biological sample analyses not typically included in standard clinical procedures was obtained from patients' relatives. Patients whose death was expected during the first $24 \mathrm{~h}$ postadmission were excluded.

Patients were resuscitated according to the Parkland formula. Emergency burn evaluation was performed at admission to detect circulatory compromise. Subsequently, escharotomies were performed

Intensive Care Unit, Hospital Universitario Virgen del Rocío, Sevilla, Andalucia, Spain

Correspondence: Dr Juan J Egea-Guerrero, Intensive Care Unit, Hospital Universitario Virgen del Rocío, Avda. Manuel Siurot s/n, Sevilla,

Andalucia, Spain 41013. Telephone 34686638646, e-mail jjegeaguerrero@gmail.com 
if necessary. Early wound burn debridement was performed within the first few days after thermal injury. Synthetic skin substitutes were used as temporary wound covers. Definitive treatment was performed through transplantation using meshed split-skin autograft.

The following clinical variables were collected at ICU admission: sex, age, cause of burn injury, whether the event occurred in an open or closed space, percentage of total burn surface area (TBSA) and severity of the thermal injury, as assessed using the Abbreviated Burn Severity Index (ABSI). This index is generated from a multivariate logistic regression analysis, which includes sex, age, presence of inhalation injury or associated trauma, depth of the lesions and percentage of TBSA. Critically burned patients score $\geq 7$ on the ABSI, or require respiratory support with mechanical ventilation, regardless of the degree and/or extent of the burn.

Clinical variables and venous blood samples for CRP and PCT determination were collected at admission and every $48 \mathrm{~h}$ thereafter until ICU discharge or death. Each day of blood extraction was considered to be a sample or unit of analysis. The samples were classified as: absence of sepsis; first day of a new onset of sepsis; or evolution of existing sepsis process. Two days without infectious symptoms was considered to be a resolved infection. If new sepsis symptoms were detected after this interval, the first day of symptom manifestation was considered to be a new onset of sepsis. To avoid potential positive interference on days of symptom evolution, only data corresponding to the first day of the new onset were analyzed. Two independent investigators, blinded to the clinical findings, conducted the sample classification using the criteria described below.

\section{SIRS and sepsis definition}

SIRS diagnosis was based on the guidelines and recommendations of the American Burn Association (9). SIRS was considered to be present when the critically burned patient demonstrated more than one of the following clinical signs: temperature $>39^{\circ} \mathrm{C}$ or $<36.5^{\circ} \mathrm{C}$; heart rate $>110$ beats $/ \mathrm{min}$; respiratory rate $>25$ breaths $/ \mathrm{min}$ not ventilated, or minute ventilation $>121$ breaths/min ventilated; leukocyte count $>12 \times 10^{9} / \mathrm{L}$ cells $/ \mathrm{mL}$ or $<4 \times 10^{9} / \mathrm{L}$; thrombocytopenia $<100,000 / \mu \mathrm{L}$ as of the third day postburn; hyperglycemia: $>11 \mathrm{mmol} / \mathrm{L}$ or insulin resistance of $>7$ units $/ \mathrm{h}$ or $>25 \%$ increase in insulin dosage over a $24 \mathrm{~h}$ period; and intolerance to enteral feedings $>24 \mathrm{~h}$.

The following internationally established diagnostic criteria were used to determine whether samples with SIRS were triggered by infectious or noninfectious conditions $(8,9)$ :

1. Respiratory sepsis: Compatible with pneumonia: appearance of new radiological lesions in chest $\mathrm{x}$-ray - persistent after negative hydric balance and/or respiratory physiotherapy, discarding cardiogenic component - with mucopurulent sputum, positive Gram stain and positive cultures, and quantitative culture analysis of the respiratory tract showing protected bronchial brush $\geq 10^{3}$ colony forming units $(\mathrm{cfu}) / \mathrm{mL}$, bronchoalveolar lavage $\geq 10^{4} \mathrm{cfu} / \mathrm{mL}$, and broncoaspirate $\geq 10^{6} \mathrm{cfu} / \mathrm{mL}$. The presence of these criteria without radiological signs indicated that the sample was secondary to tracheobronchitis.

2. Sepsis secondary to urinary tract infection: Presence of leukocyturia and urine cultures $>10^{5} \mathrm{cfu} / \mathrm{mL}$ from no more than two different germs.

3. Sepsis due to catheter-related infection: Two or more of the following criteria were met: erythema, edema or purulent exudate from the catheter tip, or fever without an underlying cause, which improved after catheter removal. Diagnosis was confirmed microbiologically when simultaneous testing detected the same germ (species and antibiogram) from the catheter tip and direct puncture hemocultures.

4. Bloodstream infection: Confirmed under clinical signs of sepsis and one of two conditions: $\geq 2$ hemocultures shared a recognized pathogen, or one hemoculture was positive; two hemocultures, extracted on separate occasions, showed repeated isolation of the same cutaneous contaminant.
5. Sepsis due to burn wound infection: Confirmed when burns present purulent secretion, colour changes, bad odour, lymphangitis, necrosis progression and graft failure, as well as microbiological results (skin biopsy) of growth $>10^{5} \mathrm{cfu} / \mathrm{g}$ of tissue or histological evidence of invasion of adjacent unburned skin/tissue.

Samples with SIRS that did not fulfill the aforementioned sepsis criteria were considered to be no-sepsis. These samples were then tested for other causes (surgery, transfusion, drugs, etc) that may underlie these symptoms.

\section{Measurement of CRP and PCT levels}

Once collected, the samples were immediately transported to the laboratory and centrifuged at $900 \times \mathrm{g}$ for $10 \mathrm{~min}$ at room temperature. CRP values, routinely measured at the authors' centre, could be used for the clinical management of patients, unlike PCT values, which were determined once the patient recruitment period ended. The separated sera were frozen in aliquots and stored at $-80^{\circ} \mathrm{C}$ until PCT analysis (20). Serum CRP quantification was performed using the particle enhanced immunoturbidimetric assay (Roche Diagnostic $\mathrm{GmbH}$, Germany). The results are given in milligrams per litre $(\mathrm{mg} / \mathrm{L})$. Detection begins at $0.3 \mathrm{mg} / \mathrm{L}$ and any concentration $>350 \mathrm{mg} / \mathrm{L}$ can be quantified without dilution. PCT serum values were measured using electrochemiluminescence using the ECLIA test, a commercially sold test produced by Elecsys BRAHMS for the immunoanalyzer Elecsys 2010 (Roche Diagnostics, Germany). This $18 \mathrm{~min}$ test has a detection limit of $0.02 \mathrm{ng} / \mathrm{mL}$ and functional sensitivity $0.06 \mathrm{ng} / \mathrm{mL}$. The biochemist performing the assay was blinded to clinical findings.

\section{Statistical analysis}

A descriptive analysis was performed using qualitative variables, represented by absolute frequencies and percentages. Quantitative variables were expressed using median and $\mathrm{SD}$, or mean and interquartile range (IQR), depending on whether they followed a normal distribution. Temporal changes in CRP and PCT values $(\Delta)$ between consecutive samples were recorded. Comparison analysis of absolute values and temporal changes in CRP and PCT levels between samples (sepsis/no-sepsis) were conducted using the Mann-Whitney U test and Wilcoxon test, respectively. ROC curve analysis were also performed. A significance level of 0.05 was applied in all statistical hypothesis testing. Statistical analyses were conducted using SPSS version 20.0 (IBM Corporation, USA).

\section{RESULTS}

Twenty-one critically burned patients were admitted to the hospital's ICU during the study period. Three patients were excluded because of high risk for mortality within $24 \mathrm{~h}$ due to the severity of their injuries, and one family declined participation on the part of their injured relative. Finally, a total of 157 samples were analyzed, corresponding to 17 critically burned patients. Mean $( \pm$ SD) age was $44.34 \pm 7.9$ years, with a higher proportion of males $(n=13[76.5 \%])$. The main cause of injury was flame burns $(\mathrm{n}=11[64.7 \%])$, followed by electrical burns $(n=4[23.5 \%]) ; 41.2 \%$ of the patients sustained injuries in a closed space. Mean percentage of TBSA was $47.43 \pm 22.9 \%$, with a mean ABSI score of $9.15 \pm 2.3$ at $24 \mathrm{~h}$. Median ICU stay was 12.5 days (IQR 5.5 to 43 days). Six (35\%) patients died during the follow-up period.

A total of 157 determinations were collected during the trial period. Of these, 54 were considered to be septic, and 25 corresponded to the first day of a new onset of sepsis. The mean duration of these symptoms was four days (IQR two to five days). The most frequent focus of infection was respiratory source $(85.7 \%)$, followed by catheterrelated infection and burn wound infection ( $4.8 \%$ in both cases).

Isolated leukocytosis or leukopenia was not associated with sepsis. Statistically significant differences were found when analyzing the distribution of CRP and PCT values between sepsis/no-sepsis samples, as shown in Figure 1. ROC curve analysis showed that CRP had an area under the curve (AUC) 0.72 (95\% CI 0.61 to $0.83 ; \mathrm{P}=0.001$ ), while PCT values had an AUC 0.71 (95\% CI 0.59 to $0.832 ; \mathrm{P}=0.002$ ) 


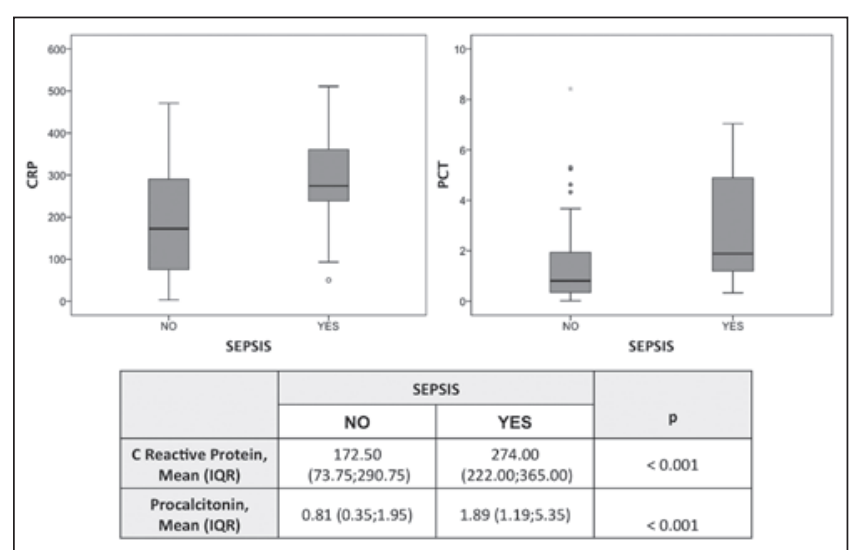

Figure 1) Box and whisker plot of C-reactive protein (CRP; $m g / L)$ and procalcitonin (PCT; $n g / m L$ ) levels depending on the sepsis/no-sepsis diagnosis. IQR Interquartile range

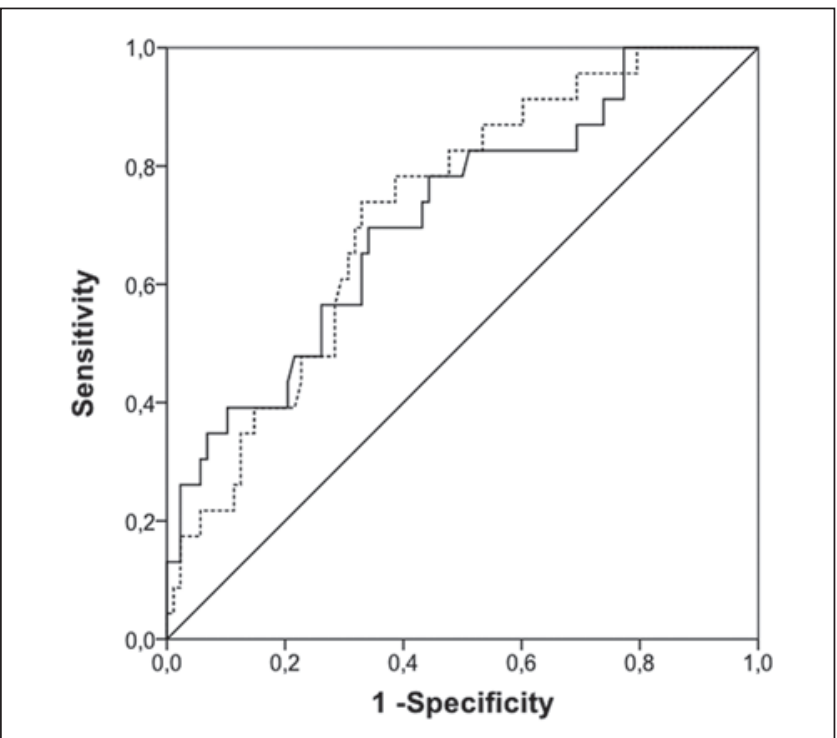

Figure 2) ROC curve analysis comparing sensitivity with 1 - specificity of C-reactive protein (dotted curve) and procalcitonin (solid curve) to determine sepsis

(Figure 2). Temporal analysis of the changes in these biomarkers indicated that changes in PCT level $(\triangle \mathrm{PCT})$ were associated with positive or negative sepsis diagnoses, whereas $\triangle \mathrm{CRP}$ were not (Figure 3 ). Increases in PCT levels correlated with $78 \%$ of positive sepsis samples, while decreases in these levels correlated with $91.1 \%$ of no-sepsis samples $(\mathrm{P}=0.001)$. The ROC curve analysis also revealed that $\triangle \mathrm{PCT}$ could predict positive sepsis samples (AUC $0.75[95 \% \mathrm{CI}$ 0.58 to 0.90 ]; $\mathrm{P}=0.003$ ), whereas $\triangle \mathrm{CRP}$ could not (AUC $0.60[95 \%$ CI 0.41 to 0.78 ]; $\mathrm{P}=0.247$ ) (Figure 4 ).

\section{DISCUSSION}

Our preliminary results show that the determinations of serum PCT and of serum CRP may help detect septic processes in severe burn patients. However, changes over time in PCT levels, as opposed to CRP levels, proved to be a more accurate predictor of sepsis.

Currently, the diagnosis of sepsis is made when a number of physiological changes occur, changes that are determined by consensus conferences (8). It is important to note the lack of a gold standard for sepsis diagnosis, which may globally encompass critical infectious disease (12). The complex pathophysiology of thermal injury and its systemic effects makes the standard criteria used to define SIRS inappropriate for severe burn patients, establishing upper cut-offs in

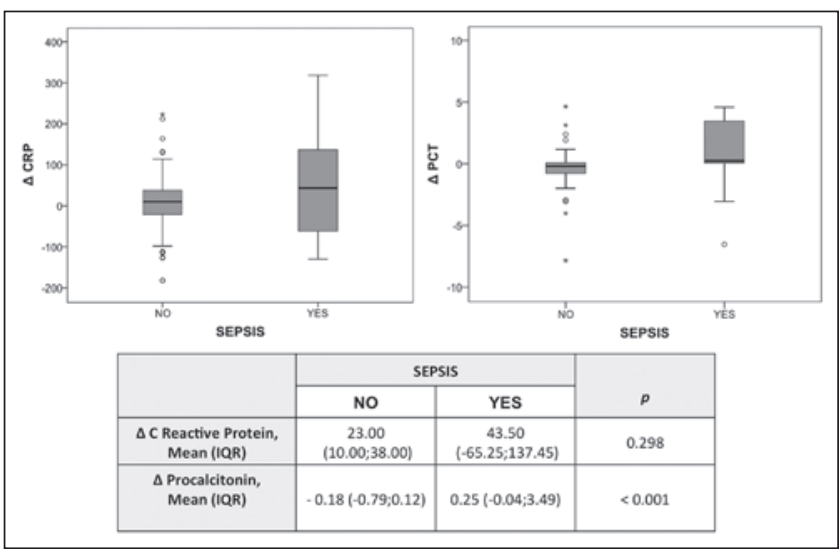

Figure 3) Box and whisker plot of changes $(\Delta)$ in C-reactive protein (CRP, $\mathrm{mg} / \mathrm{L}$ ) and $\Delta$ procalcitonin (PCT; $n g / \mathrm{mL}$ ) levels depending on the sepsis/ no-sepsis diagnosis. IQR Interquartile range

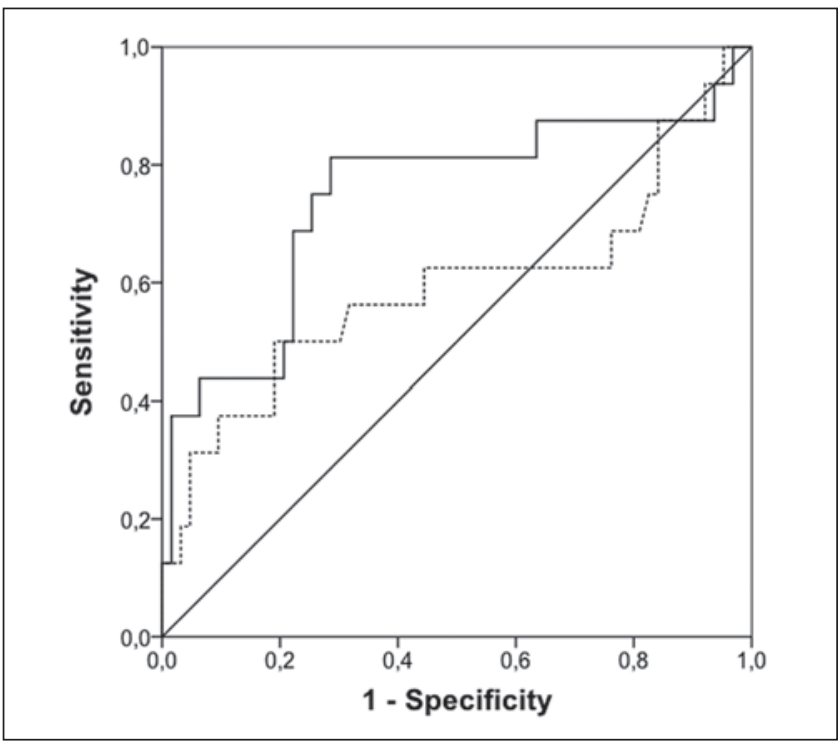

Figure 4) ROC curve analysis comparing sensitivity with 1 - specificity of changes $(\Delta)$ in C-reactive protein (dotted line) and $\Delta$ procalcitonin (solid curve) to determine sepsis

common factors, while adding variables from other syndromes (glucose tolerance and nutrition) (9). Therefore, the presence of SIRS in severe burn patients has limited clinical utility for diagnosing infection and sepsis in these patients. This has led to systematic microbiological culture testing in all burn patients with SIRS. However, the time elapsed between test completion and results confirming or ruling out sepsis often requires the physician to start early, and occasionally unnecessary, empirical antibiotic therapy. This enhances the appearance and proliferation of multiresistant bacteria and increases costs. Conversely, failure to apply early and appropriate antibiotic treatment for suspected infection is widely demonstrated to be associated with a worse prognosis in all patient groups $(5-7,21)$. Therefore, the incorporation of PCT analysis, as an objective biomarker of infection in burn patients, would lower antibiotic exposure, reduce unneeded rotations of vascular access, and decrease the number of requested microbiological determinations, both invasive and noninvasive. The end result would be increased efficiency in the management of critically burned patients.

Routine analysis of serum CRP in SIRS patient management has been identified as a marker of infection in critically ill patients, particularly in patients who experience severe blunt trauma (10). However, Gabay et al (11) list multiple events (surgery, transfusion, 
infection, etc) that increase CRP levels, suggesting a lack of specificity on the part of this biomarker as a predictive tool for sepsis. Similarly, serum CRP increments have been reported in various conditions that cause SIRS in burn patients $(17,22,23)$. We confirmed this behaviour in our population, in increments, which despite their association with sepsis samples, were not able to identify over time the onset of new infection. Therefore, although CRP maintains its role as a biomarker of inflammation in critically ill patients, its lack of precision as a marker for sepsis has led to the study of new biomarkers such as PCT.

PCT has been reported as a biomarker for sepsis with controversial results (24-26). Most studies agree that PCT is currently the most specific and early marker for sepsis. The superiority of PCT compared with CRP and other acute phase markers has been previously tested in critically ill patients. In fact, its use is recommended in patients admitted to emergency departments and has been studied in specific subpopulations of patients, such as postsurgical, oncology and transplantation patients $(13,14,27-29)$. According to research, the cutoff value for PCT levels in severe burn patients varies from $0.5 \mathrm{ng} / \mathrm{mL}$ to $3 \mathrm{ng} / \mathrm{mL}(16,18,19)$. However, it should be noted that these studies did not use the sepsis criteria applied in our research (9). To our knowledge, the only published original research applying specific sepsis criteria for burn patients is that of Lavrentieva et al (30). This study suggests that the optimal cut-off for the diagnosis of infection ranges from $1.3 \mathrm{ng} / \mathrm{mL}$ to $1.6 \mathrm{ng} / \mathrm{mL}$. However, due to methodological issues, we were unable to study this specific cut-off point in the PCT samples in our study.

As strengths of the present work, we highlight that most published studies involving burn patients apply the classic general definition of sepsis (8). As mentioned, the peculiarities and pathophysiological responses triggered by thermal injury make it necessary to apply specific guidelines for the diagnosis of sepsis in critically burned patients (9). Although they suggest the use of CRP and PCT, they fail to make definitive recommendations regarding cut-offs.

There were some limitations to the present study. First, we realize that, despite the strong number of analyzed samples, the total number of burn patients was low, although sample analysis is commonly used by several authors $(16,17)$. Nevertheless, the number of observations

\section{REFERENCES}

1. Gomez M, Cartotto R, Knighton J, Smith K, Fish JS. Improved survival following thermal injury in adult patients treated at a regional burn center. J Burn Care Res 2008;29:130-7.

2. Pham TN, Kramer CB, Wang J, et al. Epidemiology and outcomes of older adults with burn injury: An analysis of the National Burn Repository. J Burn Care Res 2009;30:30-6.

3. Duenas-Laita A, Burillo Putze G, Alonso JR, et al. Basis for the clinical management of fire smoke poisoning "Docohumo Madrid 2010". Med Intensiva 2010;34:609-19.

4. Curiel-Balsera E, Prieto-Palomino MA, Fernandez-Jimenez S, Fernandez-Ortega JF, Mora-Ordonez J, Delgado-Amaya M. Epidemiology, initial management and analysis of morbiditymortality of severe burn patient. Med Intensiva 2006;30:363-9.

5. D'Avignon LC, Hogan BK, Murray CK, et al. Contribution of bacterial and viral infections to attributable mortality in patients with severe burns: An autopsy series. Burns 2010;36:773-9.

6. Kallinen O, Maisniemi K, Bohling T, Tukiainen E, Koljonen V. Multiple organ failure as a cause of death in patients with severe burns. J Burn Care Res 2012;33:206-11.

7. Fitzwater J, Purdue GF, Hunt JL, O'Keefe GE. The risk factors and time course of sepsis and organ dysfunction after burn trauma. J Trauma 2003;54:959-66.

8. Levy MM, Fink MP, Marshall JC, et al. 2001 SCCM/ESICM/ ACCP/ATS/SIS International Sepsis Definitions Conference. Crit Care Med 2003;31:1250-6.

9. Greenhalgh DG, Saffle JR, Holmes JHT, et al. American Burn Association consensus conference to define sepsis and infection in burns. J Burn Care Res 2007;28:776-90.

10. Flores JM, Jimenez PI, Rincon D, et al. C reactive protein as marker of infection among patients with severe closed trauma. Enferm Infecc Microbiol Clin 2001;19:61-5. in our study (at admission and every $48 \mathrm{~h}$ ) enabled us to closely monitor the evolution of infectious samples during the entire stay in the ICU, rather than focus strictly on the first moments postinjury. Second, we limited part of our analysis to the first day of sepsis onset after two days without infection symptoms. This, however, kept data regarding sepsis syndromes in evolution from altering our results, given that our aim was the early detection of sepsis so that future treatment strategies could include early and justified antibiotic therapy.

The present preliminary analysis from our first year of study encourages us to continue recruiting patients to increase the patient sample and evaluate PCT performance more accurately. This would enable us to establish risk groups, and assess PCT correlations with the effectiveness of antibiotic therapy and its correlation with survival, as described in other critically ill patient populations (15,31-33). These tasks cannot be performed at present due to methodological issues.

\section{CONCLUSION}

Our results show that the role of PCT in identifying infectious processes in critically burned patients was superior to CRP in our preliminary sample. Despite this, it would be necessary to increase the sample size and include data from other centres to validate these observations.

COMPLIANCE WITH ETHICAL REQUIREMENTS: The protocol, in accordance with the Declaration of Helsinki, was approved by the Hospital's Institutional Review Board. All the ethical requirements were followed.

ACKNOWLEDGEMENTS: The invaluable collaboration of nurses in the ICU and laboratory residents is gratefully appreciated. This research was made possible, in part, by the generous collaboration of Roche Diagnostics, who provided the PCT reagents.

DISCLOSURES: Egea-Guerrero JJ, Martínez-Fernández C, Bohorquez-Lopez A, Rodríguez-Rodríguez A, Vilches-Arenas A, Pacheco-Sánchez M, Guerrero JM, Murillo-Cabezas have no financial disclosures or conflicts of interest to declare.
11. Gabay C, Kushner I. Acute-phase proteins and other systemic responses to inflammation. N Engl J Med 1999;340:448-54.

12. Becker KL, Snider R, Nylen ES. Procalcitonin assay in systemic inflammation, infection, and sepsis: Clinical utility and limitations. Crit Care Med 2008;36:941-52.

13. Uzzan B, Cohen R, Nicolas P, Cucherat M, Perret GY. Procalcitonin as a diagnostic test for sepsis in critically ill adults and after surgery or trauma: A systematic review and meta-analysis. Crit Care Med 2006;34:1996-2003.

14. Castelli GP, Pognani C, Cita M, Stuani A, Sgarbi L, Paladini R. Procalcitonin, C-reactive protein, white blood cells and SOFA score in ICU: Diagnosis and monitoring of sepsis. Minerva Anestesiol 2006;72:69-80.

15. Clec'h C, Ferriere F, Karoubi P, et al. Diagnostic and prognostic value of procalcitonin in patients with septic shock. Crit Care Med 2004;32:1166-9.

16. Lavrentieva A, Kontakiotis T, Lazaridis L, et al. Inflammatory markers in patients with severe burn injury. What is the best indicator of sepsis? Burns 2007;33:189-94.

17. Bargues L, Chancerelle Y, Catineau J, Jault P, Carsin H. Evaluation of serum procalcitonin concentration in the ICU following severe burn. Burns 2007;33:860-4.

18. von Heimburg D, Stieghorst W, Khorram-Sefat R, Pallua N. Procalcitonin - a sepsis parameter in severe burn injuries. Burns 1998;24:745-50.

19. Barati M, Alinejad F, Bahar MA, et al. Comparison of WBC, ESR, CRP and PCT serum levels in septic and non-septic burn cases. Burns 2008;34:770-4.

20. Hedelius RUD, Daheshia M, Seda G. Thermal stability evaluation of procalcitonin, a biomarker and mediator of bacterial infection. Am J Respir Crit Care Med 2013;187:A5984. 
21. Garnacho-Montero J, Garcia-Garmendia JL, Barrero-Almodovar A, Jimenez-Jimenez FJ, Perez-Paredes C, Ortiz-Leyba C. Impact of adequate empirical antibiotic therapy on the outcome of patients admitted to the intensive care unit with sepsis. Crit Care Med 2003;31:2742-51

22. Sachse C, Machens HG, Felmerer G, Berger A, Henkel E. Procalcitonin as a marker for the early diagnosis of severe infection after thermal injury. J Burn Care Rehabil 1999;20:354-60.

23. Jeschke MG, Chinkes DL, Finnerty CC, et al. Pathophysiologic response to severe burn injury. Ann Surg 2008;248:387-401.

24. Ren H, Li Y, Han C, et al. Serum procalcitonin as a diagnostic biomarker for sepsis in burned patients: A meta-analysis. Burns 2015;41: 502-9

25. Seoane L, Pértega S, Galeiras R, et al. Procalcitonin in the burn unit and the diagnosis of infection. Burns 2014;40:223-9

26. Madenci OÇ, Yakupoglu S, Benzonana N, et al. Evaluation of soluble CD14 subtype (presepsin) in burn sepsis. Burns 2014:40:664-9.

27. Leon Gil C, Garcia-Castrillo Riesgo L, Moya Mir M, et al. Consensus document (SEMES-SEMICYUC). Recommendations for the initial and multidisciplinary diagnostic management of severe sepsis in the hospital Emergency Departments. Med Intensiva 2007;31:375-87.
28. Suberviola B, Castellanos-Ortega A, Ballesteros MA, Zurbano F, Naranjo S, Minambres E. Early identification of infectious complications in lung transplant recipients using procalcitonin. Transpl Infect Dis 2012;14:461-7.

29. Aznar-Oroval E, Sanchez-Yepes M, Lorente-Alegre P, et al. Diagnostic value of procalcitonin, interleukin 8 , interleukin 6, and C-reactive protein for detecting bacteremia and fungemia in cancer patients. Enferm Infecc Microbiol Clin 2010;28:273-7.

30. Lavrentieva A, Papadopoulou S, Kioumis J, Kaimakamis E, Bitzani M. PCT as a diagnostic and prognostic tool in burn patients. Whether time course has a role in monitoring sepsis treatment. Burns 2012;38:356-63.

31. Kopterides P, Siempos, II, Tsangaris I, Tsantes A, Armaganidis A. Procalcitonin-guided algorithms of antibiotic therapy in the intensive care unit: A systematic review and meta-analysis of randomized controlled trials. Crit Care Med 2010;38:2229-41.

32. Kim HS, Yang HT, Hur J, et al. Procalcitonin levels within 48 hours after burn injury as a prognostic factor. Ann Clin Lab Sci 2012;42:57-64

33. Miguel-Bayarri V, Casanoves-Laparra EB, Pallas-Beneyto L, et al. Prognostic value of the biomarkers procalcitonin, interleukin- 6 and C-reactive protein in severe sepsis. Med Intensiva 2012;36:556-62. 